\title{
Gastrointestinal Stromal Tumors Etiology, Clinical Presentation And Review Of The Literature In Greek Patients
}

Georgios Zacharis ${ }^{1}$, Nada Zacharis ${ }^{2}$, Nikiforos Rodis ${ }^{3}$, Charalampos Potsios ${ }^{4}$, Panagiota Xaplanteri ${ }^{5^{*}}$

${ }^{1}$ General Hospital of Patras, Surgery Department, Patras, Greece

${ }^{2} \mathrm{GP}$, Internal Medicine, Patras, Greece

${ }^{3}$ Student in fifth year, Medical School, Democritus University of Thrace, Greece

${ }^{4}$ University General Hospital of Patras, Department of Internal Medicine, Patras, Greece

${ }^{5}$ School of Health Rehabilitation Sciences, Department of Nursing, University of Patras, Greece

* corresponding author: Panagiota Xaplanteri, School of Health Rehabilitation Sciences, Department of Nursing, University of Patras, Greece Received Date: March 02, 2020; Accepted Date: MaY 19, 2020; Published Date: June $06,2020$.

Citation: Zacharis G, Zacharis N, Rodis N, Potsios C, Xaplanteri P. (2020) Gastrointestinal Stromal Tumors - Etiology, Clinical Presentation and Review of the literature in Greek Patients. Journal of Surgical Case Reports and Images, 3(3): Doi: 10.31579/2690-1897/024

Copyright: ( ) 2020. : Panagiota Xaplanteri. This is an open-access article distributed under the terms of the Creative Commons Attribution License, which permits unrestricted use, distribution, and reproduction in any medium, provided the original author and source are credited.

\begin{abstract}
Gastrointestinal stromal tumors (GIST) represent rare malignancies of mesenchymal origin that can appear at any site of the gastrointestinal tract. Their classification, patient treatment and prognosis had been a source of controversy. The biology of these tumors revealed association to the type III tyrosine kinase receptor and the KIT CD117 protein expression. GIST mesenchymal lesions derive from the interstitial cells of Cajal. Classification methods include the one by Miettinen and Lasota and the "modified NIH classification". The treatment of choice is surgical intervention and complete removal of the neoplasm. In patients with tumors that cannot be excised, have given metastasis, or are of high risk for metastasis, treatment also involves Kit/PDGFRA tyrosine kinase inhibitors, such as imatinib. In Greece, several cases have been described.
\end{abstract}

Keywords: GIST, CD117; imatinib

\section{Main Document}

GISTs tumors are neoplasms of mesenchymal origin and represent 0.1 $3 \%$ of all gastrointestinal tumors. Their most frequent sites of appearance are the stomach $(60-70 \%)$, the small intestine (20-25\%), the colon and rectum $(5 \%)$ and the esophagus $(<5 \%)$, although extraintestinal sites have also been described [1,2]. The term

Gastrointestinal stromal tumors (GIST) was firstly repotred by Mazur and Clark in 1983 [3]. They used the term to characterize neoplasms of gastrointestinal tract origin that until then were falsely considered as smooth-muscle neoplasms [4]. Their classification and consequently differentiation, patient treatment and prognosis had been a source of controversy. At first they were proved to be CD34 positive, an immunopositivity related to origin of both spindle cell and epithelioid type cells. Later it proved that only $60-70 \%$ of GIST neoplasms were CD3 positive [3, 4].

The biology of these tumors revealed that mutation associated to the type III tyrosine kinase receptor and the KIT CD117 protein expression play a significant role in their appearance. The expression of KIT protein (CD117) is recognized as a reliable phenotypic marker for these neoplasms [4-6]. GIST mesenchymal lesions derive from the interstitial cells of Cajal. These cells belong to the neuromuscular apparatus of the gastrointestinal tract. They have characteristics of both smooth muscle and neuronal cells and their role is to regulate peristalsis by generating intrinsic electrical rhythmicity $[4,7]$. Mutations in Kit juxtamembrane domain (exon 11) are the most common in GISTs of all sites, whereas rare Kit extracellular domain (exon 9) Ala502-Tyr503 duplication is specific for intestinal GISTs [8]. Mutations in platelet derived growth factor receptor alpha (PDGFRA) have also been described in juxtamembrane (exon 12) and tyrosine kinase domains (exons 14 and 18) in gastric GIST tumors of epithelioid origin [8]. KIT and PDGFRA genes encode for the homologous receptor tyrosine kinase proteins. Those proteins have structural characteristics of type III receptor tyrosine kinase family and regulate cellular proliferation and apoptosis via phosphorylation. Mutations of KIT and PDGFRA permit increase in cellular proliferation and decrease the rate of apoptosis. As a result, these alterations and probably other genetic changes that follow, like loss of potential tumor suppressor genes in chromosome arms $14 \mathrm{q}$ and $22 \mathrm{q}$, lead into the development of tumor [8].

GISTs usually occur in older adults (more than 60 years of age) and are equally distributed to both sexes. The most common symptom is bleeding of the gastrointestinal tract that can be acute or chronic and the patient presents with anemia. Other symptoms depend on the location of the tumor and include abdominal pain, nausea, vomiting, or bowel obstruction $[6,8]$.

Physical examination and abdomen palpation are always the first steps to set diagnosis in combination with abdomen ultrasound [4]. In ultrasound the lesions appear as hypoechogenic masses with cystic, necrotic or haemorrhagic features

Computerized tomography (CT scan) confirms the appearance of tumor mass in the lower abdomen. [5]. CT scan without endovenous contrast reveals haemorrhage or calcification. After endovenous contrast the lesion shows heterogeneity [9]. MRI is useful in neoplasms located in the pelvic, mesenterium and peritoneum [9].

Histologically, the diagnosis of GIST falls into one of the following categories: spindle cell type (70\%), epithelioid type (20\%), or mixed type (10\%) [4]. Histological diagnosis is usually performed via echoendoscopy-guided-biopsy or CT-guided percutaneous biopsy. For 
localized disease the treatment of choice is surgery and complete excision of the tumor [4].

The presence of epithelioid cells is related to malignancy. The size of the malignancy and the mitotic rate have been associated with the outcome. A tumor larger than $5 \mathrm{~cm}$ and with more than 5 mitoses per 50 high-power fields (HPF) is very likely to lead to metastasis and is also related to 40$50 \%$ of mortality [5,6]. In addition the location of the tumor has been described by many authors as a prognostic factor, but such a fact needs more elucidation and many risk classifications have been proposed [4]. GIST tumors with recurrence or hepatic metastasis are related to poor prognosis [4]. In the National Institutes of Health (NIH) classification tumor diameter and mitotic index are used. The risk-classification method by Miettinen and Lasota also includes the tumor location. The "modified NIH classification" in addition includes the term rupture of the tumor [10].

The treatment of choice is surgical intervention and complete removal of the neoplasm. In patients with tumors that cannot be excised, have given metastasis, or are of high risk for metastasis, treatment also involves Kit/PDGFRA tyrosine kinase inhibitors, such as imatinib [8]. The standard dosage for imatinib mesylate is $400 \mathrm{mg} /$ day. The NCCN and ESMO guidelines recommend $800 \mathrm{mg} /$ day for KIT exon 9mutated GISTs because of longer progression-free survival [10]. This therapy is not successful long term as resistance via secondary mutations or clonal selection is described $[8,9]$. Resistance to imatinib is considered primary when associated with progressive disease within 6 months, and secondary when associated with progressive disease after 6 months. Primary resistance relates to the D842V mutation and some KIT exon 9 mutations. Secondary resistance is related to therapy with imatinib and is due to new mutations in two kinase domains that occur in the ATP-binding pocket or activation loop. They are related to KIT exon 11 mutations and show clonal evolution[10]. In these patients sunitinib should be used and regorafenib for patients that neither imatinib nor sunitinib can be used [4, 9].

In Greece, several cases of GIST has been described as case reports. GIST tumors originated from the jejunum have been described by Gourgiotis et al (2009) Soufleris et al (2008), Zacharis et al (2017) [6, 11, 12]. GIST tumors of the duodenum have been reported by Germanos et al (2011) [13]. GIST tumors of the ileum have been reported by Efremidou et al. (2006) [14]. GIST of colorectal origin have been described by Anagnostou et al. (2011). Dimitroulopoulos et al (2009), Kalliouris et al (2019) $[5,15,16]$. Two reports of exophytic Gastrointestinal Stromal Tumor of the Stomach have been reported by Kalliakmanis et al. (2017) [17]. A case of abdominal primary extra-gastrointestinal stromal tumor (E-GIST) has been described by Kalogeraki et al. (2015). Diagnosis was established by cytologic in ascitic fluid [18]. A case of an 80-year-old male with a simultaneous presentation of a gastric adenocarcinoma and GIST was presented by Theodosopoulos et al. (2011) [19]. In a prospective study 52 patients with GIST were analyzed by Tzilves et al. and the location of the tumors in descenting order were: stomach $(51.9 \%$ of patients), small intestine (28.8\%), colon and rectum (15.4\%) and the esophagus in one patient [20]. In another prospective study 15 patients with GIST over a 6-year period (2005-2011) were reported by Koumarianou et al. Of those, with gastric origin were $66.6 \%$, small intestine $13.3 \%$, colon $13.3 \%$, and retroperitoneal $6.6 \%$ [21].

GIST tumors although a rare entity, should always be in mind in the case of elderly patients with anemia, abdominal pain, nausea, vomiting, or bowel obstruction.

Data availability
The authors declare that the data supporting the findings of this study are available within the article

\section{Competing interests}

The authors declare that they have no competing interests.

All of the authors declare that they have all participated in the design, execution, and analysis of the paper, and that they have approved the final version. Additionally, there are no conflicts of interest in connection with this paper, and the material described is not under publication or consideration for publication elsewhere.

\section{Author Contributions}

All authors have contributed in study concept and design, data collection, data analysis and interpretation.

\section{References}

1. Suryawanshi, K.H., Patil, T.B., Damle, R.P., Dravid, N.V., Surana. A. (2014). Gastrointestinal Stromal Tumour of Small Intestine Presenting as a Mesenteric Mass. JCDR, 8, FD14FD16.

2. Sato, K., Tanaka, T., Kato, N., Ishii, T., Terao, T., Murayama, Y. (2014). Metastatic Cerebellar Gastrointestinal Stromal Tumour with Obstructive Hydrocephalus Arising from the Small Intestine: A Case Report and Review of the Literature. Case Rep Oncol Med.

3. Mazur, M.T., Clark, H.B. (1983). Gastric stromal tumours: Reappraisal of histogenesis. Am J Surg Pathol 7, 507-519.

4. Fletcher, C.D., Berman, J.J., Corless, C., Gorstein, F., Lasota, J. (2002). Diagnosis of gastrointestinal stromal tumors: A consensus approach. Hum Pathol. 33(5), 459-465.

5. Dimitroulopoulos, D., Fotopoulou, A., Xinopoulos, D., et al. (2009). Synchronous occurrence of colorectal adenocarcinoma and colonic gastrointestinal stromal tumour (GIST). A case report. Annals of Gastroenterology 22, 197-200.

6. Gourgiotis, S., Kotoulas, D., Aloizos, S., Kolovou, A., Salemis, N.S., Kantounakis, I. (2009). Preoperative diagnosis of obscure gastrointestinal bleeding due to a GIST of the jejunum: a case report. Cases J.

7. Al-Shboul, O.A. (2013). The importance of interstitial cells of cajal in the gastrointestinal tract. Saudi J Gastroenterol. 19(1), 3-15.

8. Miettinen, M., Lasota, J. (2006). Gastrointestinal Stromal Tumors Review on Morphology, Molecular Pathology, Prognosis, and Differential Diagnosis. Arch Pathol Lab Med. 130, 1466-1478.

9. Poveda, A., del Muro, X.G., Lopez-Guerrero, J.A., Cubedo, R., Martinez, V., Romero, I., et al., (2017). GEIS guidelines for gastrointestinal sarcomas (GIST). Cancer Treatment Reviews 55, 107-119.

10. Nishida, T., Blay, JY., Hirota, S., Kitagawa, Y., Kang, YK. (2016). The standard diagnosis, treatment, and follow-up of gastrointestinal stromal tumors based on guidelines. Gastric Cancer 19, 3-14.

11. Soufleris, K., Chatzimavroudis, G., Pilpilidis, J., Lazaraki, G., Zavos, C., K. Fasoulas, K., Paroutoglou, G., Kountouras, J., Katsinelos, P. (2008). Five years missed small jejunal stromal tumor (GIST) causing recurrent episodes of bleeding: Successful diagnosis by capsule endoscopy. Annals of Gastroenterology 21(3), 201-204. 
12. Zacharis, G., Zacharis, N., Potsios, C., Xaplanteri, P. (2017). Gastrointestinal Stromal Tumour of the Jejunum in an Elderly Female Patient with Atypical Symptomatology. Hellenic Journal of Surgery 89(1), 37-39.

13. Germanos, S., Bouliaris, K., Bolanis, I., Michopoulou, A., Alepas, P., Farantos, Ch. (2011). Distal Duodenectomy for a Gastrointestinal Stromal Tumour. Hellenic Journal of Surgery 83: 5 .

14. Efremidou, E.I., Liratzopoulos, N., Papageorgiou, M.S., Romanidis, K., Manolas, K.J. (2006). Perforated GIST of the Small Intestine as a Rare Cause of Acute Abdomen: Surgical Treatment and Adjuvant Therapy. Case Report. J Gastrointestin Liver Dis. 15(3), 297-299.

15. Anagnostou, E., Miliaras, D., Panagiotakopoulos, V. (2001). Diagnosis of Gastrointestinal Stromal Tumor (GIST) on Transurethral Resection of the Prostate: A Case Report and Reviewof the Literature. International Journal of Surgical Pathology. 19(5), 632-636.

16. Kalliouris, D.N., Nikou, E., Zaravinos, S., Manesis, K., Oikonomou, C., Lingria, A., Karameris, A., Alexandrakis, G., Skandalakis, P., Filippou, D. (2019). A rare case of Wild-Type GIST of descending colon with GANT characteristics. The Turkish Journal of Gastroenterology : the Official Journal of Turkish Society of Gastroenterology, 30(6), 573-575.
17. Kalliakmanis, V., Koutsouvas, K., Dimakopoulou, V., Siasos, N. (2017). Hellenic Journal of Surgery 89(2), 87-91.

18. Kalogeraki, A., Tamiolakis, D., Papadakis, M., Moustou, E., Datseri, G., Tzardi, M. (2015). Abdominal primary extragastrointestinal stromal tumor (E-GIST). A cytologic diagnosis in ascitic fluid. Letter to the Editor. Rev. esp. enferm. dig. 107(8),

19. Theodosopoulos, T., Dellaportas, D., Psychogiou, V., Gennatas, K., Kondi-Pafiti,. (2011). Synchronous gastric adenocarcinoma and gastrointestinal stromal tumor (GIST) of the stomach: A case report. World Journal of Surgical Oncology 9, 60. doi.org/10.1186/1477-7819-9-60

20. Tzilves, D., Pilpilidis, I., Gatopoulou, A., Xiroy, P., Lazaraki, G., Patakiouta, P., Tarpagos, A. (2013). Characteristics and outcome of Gastrointestinal Stromal Tumors (GIST): A single center experience over a decade. Annals of Oncology 24 (4), iv38-iv121.

21. Koumarianou, A., Economopoulou, P., Katsaounis, P., Laschos, K., Arapantoni-Dadioti, P.,. (2015). Gastrointestinal Stromal Tumors (GIST): A Prospective Analysis and an Update on Biomarkers and Current Treatment Concepts. Biomarkers in Cancer. 7(S1), 1-7.

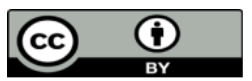

This work is licensed under Creative Commons Attribution 4.0 License
To Submit Your Article Click Here: Submit Manuscript

DOI: $10.31579 / 2690-1897 / 024$

\footnotetext{
Ready to submit your research? Choose Auctores and benefit from:

* fast, convenient online submission

* rigorous peer review by experienced research in your field

* rapid publication on acceptance

* authors retain copyrights

* unique DOI for all articles

* immediate, unrestricted online access
}

At Auctores, research is always in progress.

Learn more https://www.auctoresonline.org/journals/journal-of-surgicalcase-reports-and-images 